\title{
Numerical analysis of the influence of fastener disposition on the behaviour of timber-framed walls with wood-based sheathing boards
}

\author{
M. Premrov \& P. Dobrila \\ University of Maribor, Faculty of Civil Engineering, Slovenia
}

\begin{abstract}
This paper provides numerical analysis of the influence of fastener disposition on the behaviour of timber-framed walls, coated with single wood-based sheathing boards fastened to a timber frame. As the walls under a horizontal load actually behave like a deep composite beam, the disposition of the fasteners is very important and directly influences the bearing capacity, as well as the stiffness of the wall. This analysis is done on a special semi-analytical mathematical model that is based on a composite cantilever using the so-called " $\gamma$-method" in dependence of any possible spacing between the fasteners. It is demonstrated that the lateral stresses acting on one fastener usually reach the yielding point before any crack appears in the sheathing boards and the normal stresses in the timber frame are rather under the characteristic timber strength for any spacing between the fasteners. The obtained numerical results are supported with the measured ones from our previous experimental study.
\end{abstract}

Keywords: timber structures, walls, oriented strand boards, fasteners, numerical analysis.

\section{Introduction}

Timber is commonly associated with lightweight construction, although it is ubiquitous as a building material. Timber construction is an important part of the infrastructure in a number of areas around the world. Well-built timber structures usually maintain good performance under the influence of wind and especially earthquake forces. Nowadays, there are the strongest arguments for building timber frame buildings. Brand new and improved features, introduced in the early 1980s, brought about the expansion of timber frame buildings all over the 
world. The most important changes are introduced next: a.) transition from onsite construction to prefabrication in factories, b.) transition from elementary measures to modular building, c.) bigger input of glued-laminated wood in construction, d) development from micro-panel wall system to macro-panel wall prefabricated panel system. This paper deals with the timber-frame panel system, where the basic vertical load bearing elements are panel walls consisting of a load bearing timber frame and sheathing boards (Figure 1), while the horizontal floor load bearing elements are slabs constructed of timber beams and woodbased sheathing boards on the upper side of the beams.

This paper is focused on the structural behaviour of the timber-framed walls as the main vertical bearing capacity elements in light timber-framed buildings. The presented study is a continuation of our numerical and experimental research work [1-3] realized in recent years in reinforcing and modelling prefabricated timber-framed wall elements with fibre-plaster sheathing boards (FPB). The aim of this paper is a deep numerical analysis of the fastener disposition's influence on the behaviour of the described wall elements covered with wood-based sheathing boards (WBB) under a quasi-statically horizontal force acting at the top of the wall (Figure 2).

\section{Design models}

Many design models have been proposed in order to analyse and predict the behaviour of the wall assembly subjected to lateral loads. Load distribution on separate walls in one level of the wall assembly is calculated according to the static design presented in Figure 2. The wall units can be regarded separately for

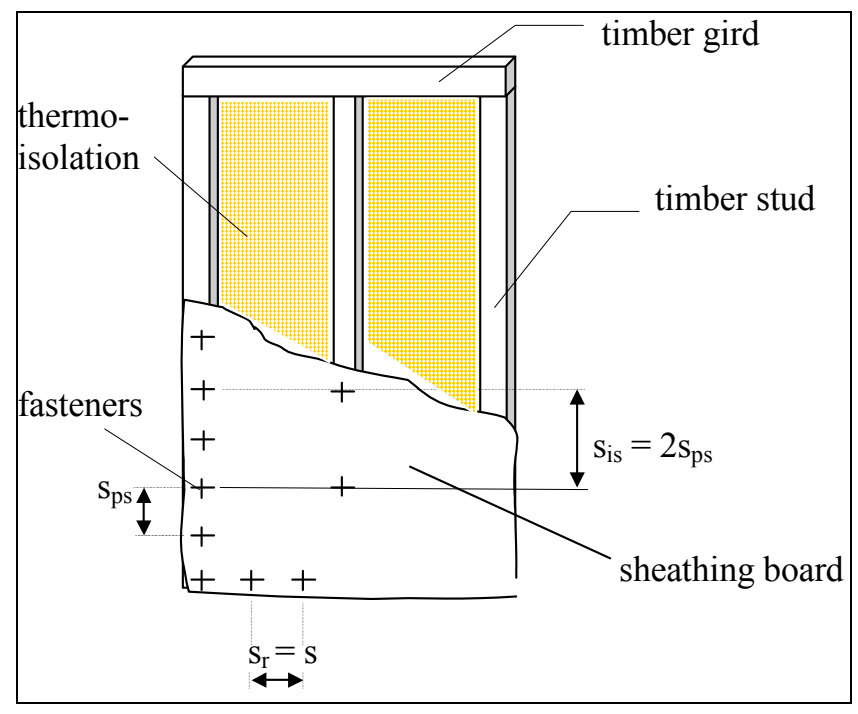

Figure 1: Composition of the timber-framed wall element. 


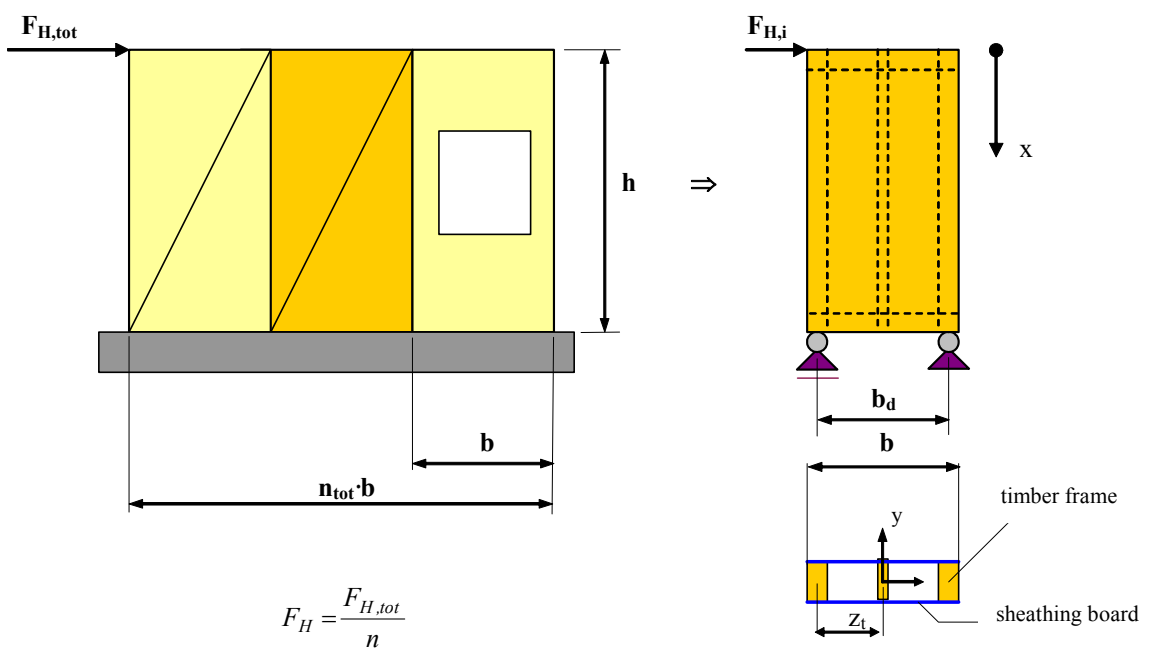

Figure 2: $\quad$ Static design for the wall assembly in one level.

design purposes as vertical cantilever beams with the horizontal force $\left(F_{H, i}=F_{H, t o t}\right.$ $/ n$ ) acting at the top. For a wall made up of several wall panels the characteristic racking load-carrying capacity of a wall should be calculated from:

$$
F_{v, R k}=\sum_{i=1, N} F_{i, v, R k}
$$

where $F_{i, v, R k}$ is the characteristic racking load-carrying capacity of the wall panel, calculated in accordance with Eq. (2).

Two simplified computational methods are given in Eurocode 5 [4] in order to determine the load-carrying capacity of the wall diaphragm. The first - Method $A$, is identical to the "Lower bound plastic method", presented by Källsner and Lam [5]. This method defines the wall's characteristic racking resistance $\left(F_{i, v, R k}\right)$ as a sum of fasteners' characteristic lateral load-carrying capacity $\left(F_{f, R k}\right)$ along the loaded edges using assumptions that the timber frame members and the sheets are rigid and hinged to each other, the spacing of fasteners is constant along the perimeter of every sheet and the width of each sheet is at least $h / 4$ :

$$
\begin{gathered}
F_{i, v, R k}=\sum F_{f, R k} \cdot \frac{b_{i}}{s} \cdot c \\
c=\left\{\begin{array}{l}
1 \quad \text { for } b \geq b_{0} \\
\frac{b_{i}}{b_{0}} \text { for } b \leq b_{0} \quad \text { where } b_{0}=h / 2
\end{array}\right.
\end{gathered}
$$


The horizontal displacement $\left(u_{\text {frame }}\right)$ of the top rail of the shear wall of the mentioned common wall design including an influence of the shear modulus of the sheet $\left(G_{b}\right)$ is given by Källsner [6] in the form of:

$$
u_{\text {frame }}=\left[4.535+\frac{h_{i}}{b_{i}} \cdot \frac{K}{G_{b} \cdot t} \cdot \frac{b_{i}}{s_{r}}\right] \cdot \frac{s_{r}}{b_{i}} \cdot 0.40 \cdot \frac{F_{H, i}}{K}
$$

where $K$ denotes a slip modulus per shear plane per fastener and $t$ is the thickness of the sheet.

\section{Semi-analytical modelling of the distribution influence of fasteners using a composite beam model}

By employing WBB as a coating material, a horizontal load shifts a part of the force over the mechanical fasteners to the board and the wall acts like a deep composite beam with a semi rigid connecting area between the timber frame and the sheathing boards. Early models and methods developed and used specifically in Germany (Henrici [7]) can basically be divided into two overall types of structural systems:

a.) the wall element is modelled as a truss system,

b.) the wall element is modelled as a composite cantilever.

In our study we will use the second one where the bottom of the wall is builtin to the floor or foundation and the composite horizontal cross-section is thus subjected to a maximum bending moment $\left(F_{H, i} \cdot h_{i}\right)$ at the built-in end (Figure 2). The publications of Cziesielski [8] and Henrici [9] are examples of such studies. In Premrov et al. [1] and in Premrov and Dobrila [2] we developed special semianalytical mathematical models based on the composite cantilever using socalled " $\gamma$-method" - a simplified design method for mechanically jointed beams according to Annex B of Eurocode 5 [4]. The expression of the method is based on the differential equation for the partial composite action with the following fundamental assumptions:

a) Bernoulli's hypothesis is valid for each sub-component,

b) slip stiffness is constant along the element,

c) material behaviour of all sub-components is linear elastic until crack appearing.

Using the $\gamma$-method the effective bending stiffness $\left(E I_{y}\right)_{\text {eff }}$ of mechanically jointed beams can be written in the form of:

$$
\left(E I_{y}\right)_{e f f}=\sum_{i=1}^{n} E_{i} \cdot\left(I_{y i}+\gamma_{y i} \cdot A_{i} \cdot a_{i}^{2}\right)
$$

where $n$ is the total number of elements in the considered cross-section and $a_{i}$ is a distance between global $\mathrm{y}$-axis of the whole cross-section and local $\mathrm{y}_{\mathrm{i}}$-axis of the i-th element with a cross-section $A_{i}$ (see Figure 2). The equation shows that the bending stiffness $\left(E I_{y}\right)_{\text {eff }}$ strongly depends on the stiffness coefficient of the 
fasteners $\left(\gamma_{y}\right)$. Respecting Eurocode 5 [4] it can be defined via the fastener spacing $(s)$ and the slip modulus per shear plane per fastener $(K)$ in the form of:

$$
\gamma_{y}=\frac{1}{1+\left(\frac{\pi^{2} \cdot A_{t 1} \cdot E_{t} \cdot s}{L_{e f f}^{2} \cdot K}\right)}
$$

It is obvious that the influence of fasteners spacing $(s)$, see Figure 1, is very important for the horizontal force distribution between the timber frame and the WBB. The horizontal force forming the first tensile crack $\left(F_{i, c r}\right)$ in WBB is defined according to the bending normal stress criteria and the tensile strength of $\operatorname{WBB}\left(f_{b t}\right)$ :

$$
F_{i, c r}=\frac{2 \cdot f_{b t}}{E_{b} \cdot b \cdot h_{d}} \cdot \frac{\left(E I_{y}\right)_{\text {timber }}+\left(E I_{y}\right)_{W B B}}{1+\left(\frac{\pi^{2} \cdot A_{t 1} \cdot E_{t} \cdot s}{L_{e f f}^{2} \cdot K}\right)}
$$

The value of the slip modulus $(K)$ in Eq. (5) depends on the lateral force $\left(F_{l}\right)$ acting on one fastener in a single shear, calculated in the form of:

$$
F_{1}=\frac{\left(E S_{y}\right)_{e f f}}{\left(E I_{y}\right)_{e f f}} \cdot \frac{s}{2} \cdot V_{z}=\frac{\left(E S_{y}\right)_{e f f}}{\left(E I_{y}\right)_{e f f}} \cdot \frac{s}{2} \cdot F_{H, i}
$$

As long as behavior of the fasteners is almost elastic, the value of $K$ is maximal $\left(K=K_{s e r}\right)$ and it is constant. Expressions for various types of fasteners can be found in Eurocode 5 [4]. In the proposed mathematical model the value of the modulus $K$ varies according to the lateral force $\left(F_{l}\right)$ acting on one fastener with a three-linear diagram. It is important to determine three fundamental diagram points:

$$
\begin{gathered}
F_{1} \leq N_{a l} \quad \Rightarrow \quad K=K_{s e r} \\
F_{1}=F_{f, R d} \Rightarrow K=K_{u}=\frac{2}{3} \cdot K_{s e r} \\
F_{1}=F_{f, R k} \quad \Rightarrow \quad K=0
\end{gathered}
$$

where $N_{a l}$ is allowable lateral load-bearing capacity per shear plane per fastener, $F_{f, R d}$ is design lateral load-bearing capacity per shear plane per fastener and $F_{f, R k}$ is characteristic lateral load-bearing capacity per shear plane per fastener. For intermediate values of $F_{l}$ linear interpolation is used.

Respecting the serviceability limit state conditions it is important to calculate a maximal horizontal displacement $(u)$ at the top of the wall. It can be obtained by using the cantilever beam model in a form of:

$$
u=\int_{x=0}^{x=h_{d}} \frac{F_{H, i} \cdot x^{2}}{\left(E I_{y}\right)_{e f f}} d x+\int_{x=0}^{x=h_{d}} \frac{F_{H, i}}{\left(G A_{s}\right)_{e f f}} d x+\frac{F_{H, i} \cdot h_{d}}{n \cdot K_{s e r, M}}
$$


where the first term presents the bending deflection, the second the shear deformation of the board and the last the deformability influence of the anchors.

\section{Numerical example}

Numerical analysis is performed for the panel wall of actual dimensions $h_{i}=263.5 \mathrm{~cm}$ and $b_{i}=125 \mathrm{~cm}$, composed of timber studs $(2 \times 9 \times 9 \mathrm{~cm}$ and $1 \times 4.4 \times 9 \mathrm{~cm})$ and timber girders $(2 x 8 \times 9 \mathrm{~cm})$. The boards of the thickness $t=15 \mathrm{~mm}$ are fixed to the timber frame using staples of $d=1.53 \mathrm{~mm}$ and length $l=35 \mathrm{~mm}$ (Figure 3). Eurocode 5 defines that a minimum spacing for staples is $a_{1}=(10+$ $5|\cos \alpha|) d=15 d=22.95 \mathrm{~mm}$.

The tensile support is simulated with three M16 bolts and with two thin steel plates $(5 \times 120 \times 600 \mathrm{~mm})$. These steel plates are anchored to the rigid steel frame over 2 [NP10 using two tensile M16 bolts of length $l_{1}=210 \mathrm{~mm}$.

Material properties for the timber of quality $\mathrm{C} 22$ are taken from [10] and for OSB 3 from [11]. They are listed in Table 1.

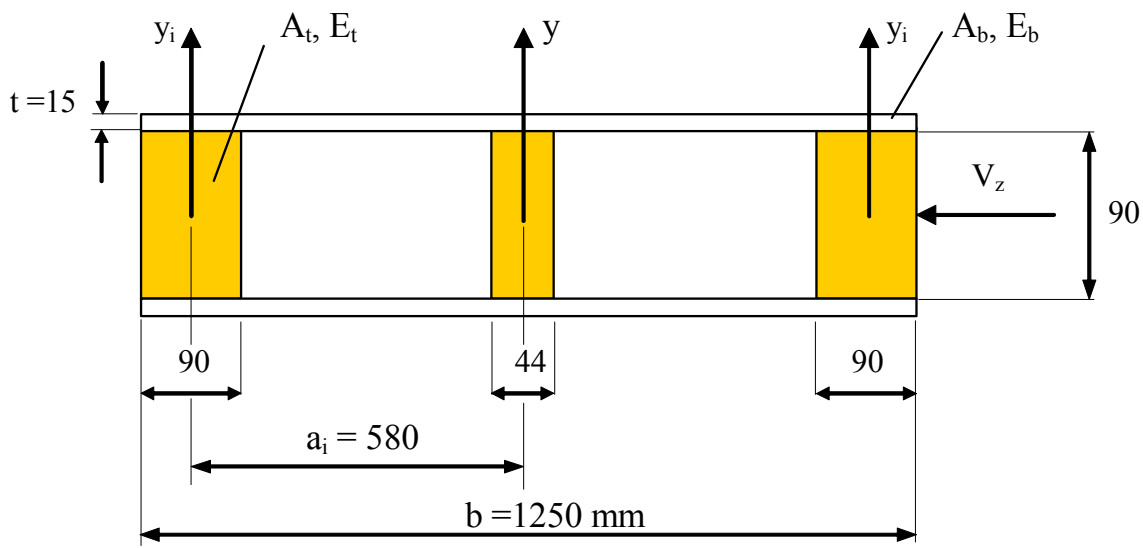

Figure 3: Cross-section of the test sample.

Table 1: $\quad$ Properties of the used materials.

\begin{tabular}{|l|c|c|c|c|c|c|c|}
\hline & $\begin{array}{c}\mathrm{E}_{0, \mathrm{~m}} \\
{\left[\mathrm{~N} / \mathrm{mm}^{2}\right.} \\
]\end{array}$ & $\begin{array}{c}\mathrm{G}_{\mathrm{m}} \\
{\left[\mathrm{N} / \mathrm{mm}^{2}\right.} \\
]\end{array}$ & $\begin{array}{c}\mathrm{f}_{\mathrm{m}, \mathrm{k}} \\
{\left[\mathrm{N} / \mathrm{mm}^{2}\right.} \\
]\end{array}$ & $\begin{array}{c}\mathrm{f}_{\mathrm{t}, 0, \mathrm{k}} \\
{\left[\mathrm{N} / \mathrm{mm}^{2}\right.} \\
]\end{array}$ & $\begin{array}{c}\mathrm{f}_{\mathrm{c}, 0, \mathrm{k}} \\
{\left[\mathrm{N} / \mathrm{mm}^{2}\right.} \\
]\end{array}$ & $\begin{array}{c}\mathrm{f}_{\mathrm{v}, \mathrm{k}} \\
{\left[\mathrm{N} / \mathrm{mm}^{2}\right.} \\
]\end{array}$ & $\begin{array}{c}\rho_{\mathrm{m}} \\
{\left[\mathrm{kg} / \mathrm{m}^{3}\right.} \\
]\end{array}$ \\
\hline $\mathrm{C} 22$ & 1000 & 630 & 22 & 13 & 20 & 2.4 & 410 \\
\hline $\begin{array}{l}\text { OSB } \\
3\end{array}$ & 3500 & 240 & 20 & 20 & 20 & 5.0 & 600 \\
\hline
\end{tabular}


The characteristic lateral load-carrying capacity of the staples $F_{f, R k}=$ $644.291 N$ is obtained according to Eurocode 5 [4] using the Johansen expressions. The belonging designed value $F_{f, R d}=446.048 \mathrm{~N}$ is gained by respecting $k_{\text {mod }}=0$.9. Allowable lateral load-bearing capacity per shear plane per fastener $\left(N_{a l}\right)$ is not declared in Eurocode 5, thus it can be obtained for the both types of the boards using Brüninghoff et al. [12] $N_{a l}=307.619 \mathrm{~N}$. Slip modulus $\left(K_{s e r}\right)$ is computed using Eurocode 5 [4] empirical expressions in the form of:

$$
\begin{aligned}
& \rho_{m}=\sqrt{\rho_{b} \cdot \rho_{t}}=\sqrt{600 \cdot 410}=495.984 \mathrm{~kg} / \mathrm{m}^{3} \\
& K_{\text {ser }}=\frac{\rho_{m}^{1.5} \cdot d^{0.8}}{80}=\frac{495.984^{1.5} \cdot 1.53^{0.8}}{80}=194.021 \mathrm{~N} / \mathrm{mm}
\end{aligned}
$$

The characteristic racking resistance of the wall element in accordance with Eurocode 5 Method A is calculated by Eq. (2):

$$
F_{i, v, R k}=\sum F_{f, R k} \cdot \frac{b_{i}}{s} \cdot c=0.644 \cdot \frac{125 \cdot 2}{s}=\frac{161.075}{s}
$$

The characteristic horizontal force forming the first tensile crack in OSB sheathing can be calculated using Eq. (6):

$$
\begin{aligned}
& F_{i, c r, k}=\frac{2 \cdot f_{b t}}{E_{b} \cdot b \cdot h_{d}} \cdot \frac{\left(E I_{y}\right)_{\text {timber }}+\left(E I_{y}\right)_{W B B}}{1+\left(\frac{\pi^{2} \cdot A_{t 1} \cdot E_{t} \cdot s}{L_{e f f}{ }^{2} \cdot K}\right)}= \\
& =3.592 \cdot 10^{-7} \cdot\left(1.721 \cdot 10^{8}+5.450 \cdot 10^{8} /(1+0.795 \mathrm{~s})\right)
\end{aligned}
$$

The both calculated values for wall's characteristic racking resistance from Eqs. (11) and (12) are presented in Figure 4.

It is presented that the value $F_{i, v, R k}$ obtained by the shear model is far under the force appearing the first crack in the board $\left(F_{i, c r, k}\right)$ for any value of fastener's spacing $(s)$. Therefore, the fastener yielding is decisive for practically any value of $s$. The difference between the both values strongly depends on the fastener's spacing and it is smaller by a lower value of $s$.

Using Eq. (7) the lateral force $\left(F_{l}\right)$ acting on one fastener is calculated by appearing the first tensile crack in the sheathing board. The obtained results in a function of $(s)$ are graphically presented in Figure 5.

It is evident that the lateral force $\left(F_{l}\right)$ is higher than the characteristic lateral load-carrying capacity of the staples $F_{f, R k}=644.291 \mathrm{~N}$ by any useful fastener spacing $\left(s>a_{1}\right)$. It practically proves our previous state from Figure 4 that fasteners yielding appear before any cracks are formed in the boards. 


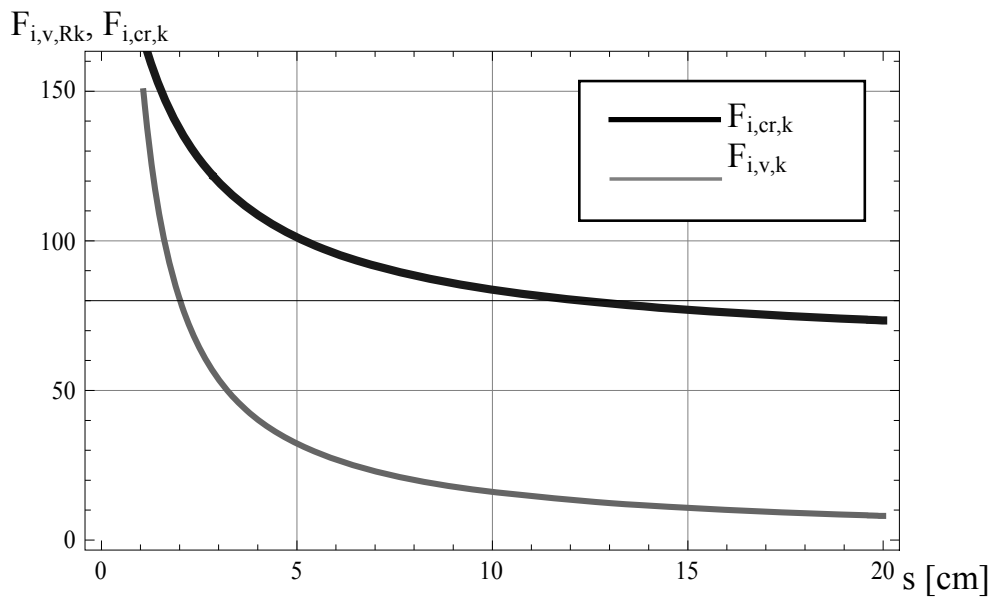

Figure 4: The characteristic racking resistance of the wall in dependence of fastener spacings (s).

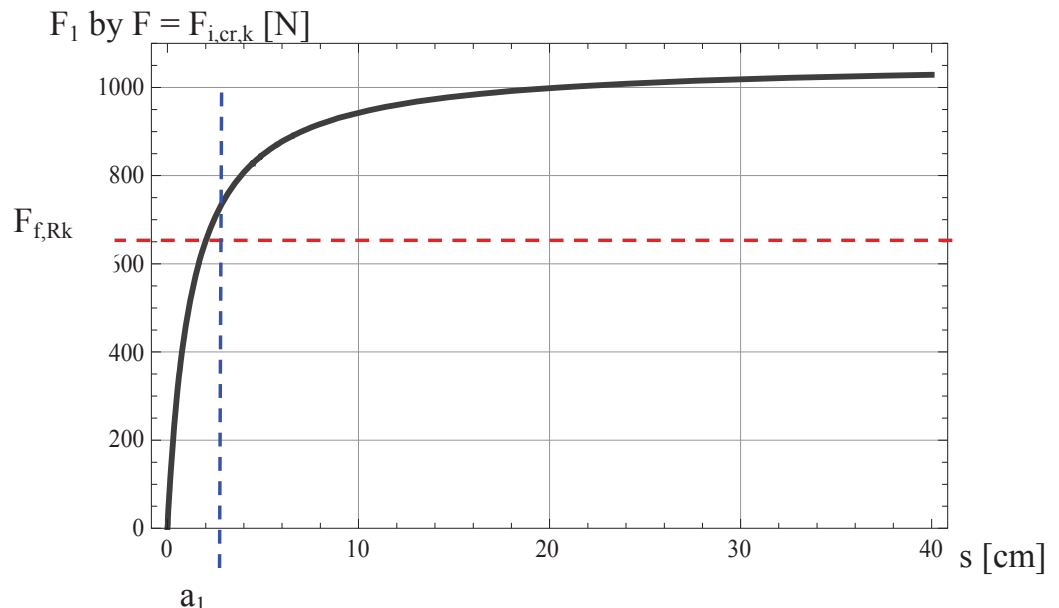

Figure 5: Lateral force acting on one fastener in dependence of fastener spacings (s).

Finally, present a comparison in results for a maximal horizontal displacement $(u)$ at the top of the wall. The results obtained by the composite beam model using Eq. (9) and the linear-elastic model using Eq. (3) are presented in Figure 6 under the horizontal force $F_{H, i}=15 \mathrm{kN}$. 


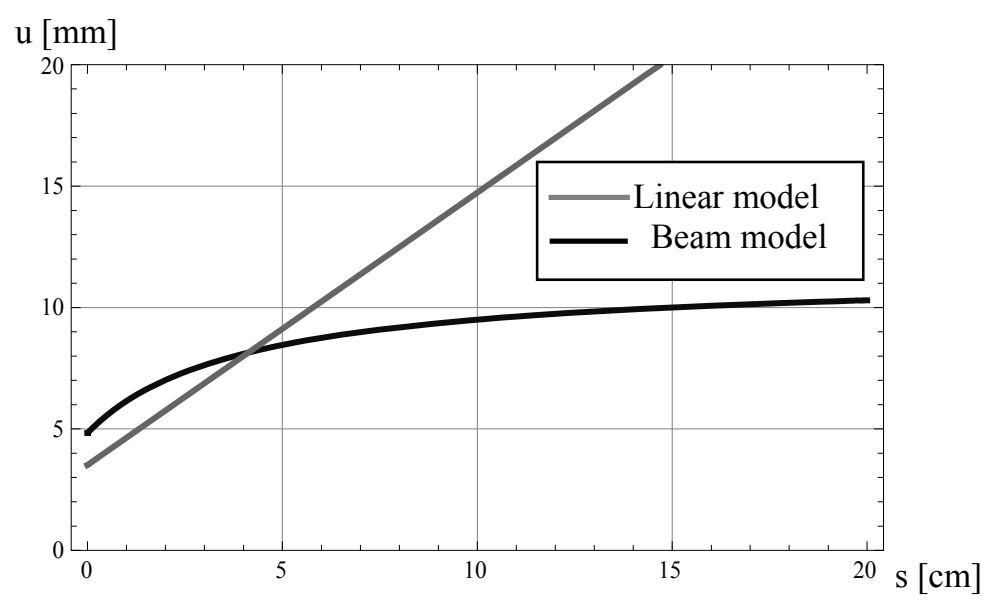

Figure 6: Maximal horizontal displacement in dependence of fastener spacings by $\mathrm{F}_{\mathrm{H}, \mathrm{i}}=15 \mathrm{kN}$.

\section{Conclusions}

It is numerically demonstrated that fasteners spacing $(s)$ has an important influence on horizontal resistance and stiffness of the presented prefabricated wall elements made of typical production dimensions. It is presented that in case of using wood-based sheathing boards there is practically no danger of any cracks appearing in the sheathing material. The lateral force $\left(F_{l}\right)$ acting on one fastener in a single shear reach the yielding point before crack appearing for practically any useful fastener spacing $\left(s>a_{1}\right)$.

Therefore, it can be concluded that the Eurocode 5 simplified methods are suitable for any fastener spacing commonly used in the production in a case of using wood-based sheathing boards. However, it is not correct by using fibreplaster sheathing material, where the tensile strength is very low and the cracks usually appear before the stresses in the fasteners achieve the yielding point [13]. Therefore, in such cases only, it is important to respect the values obtained by the presented composite beam model.

\section{References}

[1] Premrov M., Dobrila P., Bedenik B.S., Analysis of timber-framed walls coated with CFRP strips strengthened fibre-plaster boards. International Journal of Solids and Structures 41 (24/25), p.7035-7048, 2004.

[2] Premrov M., Dobrila P., Modelling of Fastener Flexibility in CFRP Strengthened Timber-Framed Walls Using Modified $\gamma$ - Method. Engineering Structures 30 (2), p.368-375, 2007. 
[3] Premrov M., Kuhta M., Influence of Fasteners Disposition on Behaviour of Timber-Framed Walls with Single Fibre-Plaster Sheathing Boards. Construction and Building Materials, 2008.

[4] CEN/TC 250/SC5 N173. Eurocode5: Design of Timber Structures, Part 1-1 General rules and rules for buildings, EN 1995-1-1, Brussels 2004.

[5] Källsner B., Lam F., Diaphragms and shear wall. Holzbauwerke: Grundlagen, Entwicklungen, Ergänzungen nach Eurocode 5, Step 3, Düsseldorf, p.15/1-17, 1995.

[6] Källsner B., Girhammar U.A., Analysis of fully anchored light-frame timber shear walls-elastic model. Materials and Structures, Vol. 42, No. 3, pp.301320, 2009.

[7] Henrici D., Berechnung von Wandscheiben. Kapitel 5 in: Konstruktion und Berechnung von Holzhäusern in Tafelbauart, hrsg. von E. Cziesielski, Expert Verlag, 1984.

[8] Cziesielski E., Stabilität von Holzhäusern unter Horizontalbelastung. Bauen mit Holz 84(7), p.446-450, 1982.

[9] Henrici D. Zur Bemessung windaussteifender hölzerner Wandscheiben. Bauen mit Holz 86(12), pp.873-877, 1984.

[10] European Committee for Standardization, EN 338:2003 E: Structural timber - Strength classes, Brussels, 2003.

[11] Kronopol OSB, Kronopol Swiss Krono Group, 2004.

[12] Brüninghoff, H., et al., Eine Ausführliche Erläuterung zu DIN 1052, Teil 1 bis Teil 3. Beuth -Kommentare, Beuth Bauverlag, Berlin, 1988. 